\title{
Instituições de educação superior do Paraná: atuação e formação de coordenadores de curso para uma gestão democrática
}

\section{Institutions of higher education in Paraná: acting and training of course coordinators for a democratic management}

\section{Instituciones de educación superior de Paraná: actuación y formación de coordinadores de curso para una gestión democrática}

\author{
Eduardo Felipe Hennerich Pacheco ${ }^{1}$ \\ Sirley Terezinha Filipak ${ }^{1}$ \\ Maria Lourdes Gisi ${ }^{1}$ \\ Antonio de Souza Júnior ${ }^{1}$
}

DOI: http://dx.doi.org/10.20435/serie-estudos.v20i52.1188

\begin{abstract}
Resumo: O objeto de estudo deste artigo são as instituições universitárias do estado do Paraná e tem como objetivo analisar a formação e atuação dos coordenadores de curso. Argumenta-se que a coordenação de cursos de graduação nas universidades deve compreender uma formação que contribua com uma gestão democrática, que se torna fundamental no contexto das transformações políticas e econômicas que vêm sendo implantadas nas últimas décadas no país, com ênfase em uma gestão gerencial. Preservar as instituições, cuja existência é fundamental para a democracia no país, é fundamental, em especial, nestes tempos em que se vive uma crise das democracias. Para tanto, foi desenvolvida uma investigação com abordagem qualitativa, mediante análise da legislação vigente sobre a educação superior, dados do Censo da Educação Superior e aplicação de questionário aos coordenadores de curso. São apresentados dados sobre as características das universidades e aspectos relacionados à formação continuada e à atuação e à escolha dos coordenadores de curso, contemplando uma análise sobre a gestão democrática.
\end{abstract}

Palavras-chave: universidade; gestão educacional; formação continuada.

Abstract: The object of study of this article are the university institutions of the State of Paraná and aims to analyze the training and performance of course coordinators. It is argued that the coordination of undergraduate courses in universities should include training that contributes

\footnotetext{
${ }^{1}$ Pontifícia Universidade Católica do Paraná (PUCPR), Curitiba, Paraná, Brasil.
} 
to democratic management, which becomes fundamental in the context of the political and economic transformations that have been implemented in the last decades in the country, with emphasis on managerial management. Preserving the institutions whose existence is fundamental to democracy in the country is fundamental, especially in these times when a crisis of democracies is underway. For that, a research with a qualitative approach was developed, through analysis of current legislation on higher education, data from the Higher Education Census and questionnaire application to course coordinators. Data on the characteristics of universities and aspects related to continuing education and to the performance and choice of course coordinators are presented, including an analysis of democratic management.

Keywords: university; educational management; continuing education.

Resumen: El objeto de estudio de este artículo son las instituciones universitarias del estado de Paraná y tiene como objetivo analizar la formación y actuación de los coordinadores de curso. Se argumenta que la coordinación de cursos de graduación en las universidades debe comprender una formación que contribuya con una gestión democrática, que se vuelve fundamental en el contexto de las transformaciones políticas y económicas que vienen siendo implantadas en las últimas décadas en el país, con énfasis en una gestión gerencial. Preservar las instituciones, cuya existencia es fundamental para la democracia en el país, es fundamental, en especial, en estos tiempos en que se vive una crisis de las democracias. Para ello, se desarrolló una investigación con abordaje cualitativo, mediante análisis de la legislación vigente sobre la educación superior, datos del Censo de la Educación Superior y aplicación de cuestionario a los coordinadores de curso. Se presentan datos sobre las características de las universidades y aspectos relacionados a la educación continua y a la actuación y a la elección de los coordinadores de curso, contemplando un análisis sobre la gestión democrática.

Palabras clave: universidad; gestión educativa; formación continua.

\section{INTRODUÇÃO}

O presente artigo insere-se em uma pesquisa que tem nos gestores de universidades do Paraná o foco principal de sua análise, considerando, em especial, a sua atuação e formação. Argumenta-se que a coordenação de cursos de graduação nas universidades deve compreender uma formação que contribua com uma gestão democrática, um requisito que assume ainda maior importância considerando as significativas transformações políticas e econômicas que vêm sendo implantadas nas últimas décadas no país, com ênfase em uma gestão gerencial voltada à produtividade e à performatividade (OLIVEIRA, 2013; BALL, 2014). São tempos em que, como afirma Severino (2016, p. 7), “[...] prevalece uma mentalidade de exacerbado pragmatismo", que contribui para reduzir o papel da educação universitária, a qual "[...] tem por finalidade intrínseca fundamental contribuir para a formação humana, entendida como processo de humanização”, finalidade que, ao ser assumida, poderia evitar que a universidade caminhe, como 
Instituições de educação superior do Paraná: atuação e formação de coordenadores de curso para uma gestão democrática

indica Sguissardi (2008, p. 993), a uma "[...] estreita e neopragmática sociabilidade produtiva".

Ocorre que nesse contexto, em que são valorizados os testes comparativos internacionais, a avaliação de desempenho, a promoção diferenciada dos docentes e a avaliação institucional, é exigido dos(as) gestores(as) uma atuação que se distancia do trabalho pedagógico e da gestão democrática. Daí a importância de repensar a atuação e a formação dos(as) coordenadores(as) de curso, para que a universidade cumpra seu papel como instituição,

[...] por excelência da cultura, do aprendizado e do cultivo da leitura, do estudo, da escrita, da dúvida, da reflexão, da civilização, da filosofia. Das letras, das artes, das ciências e da tecnologia, cabe à universidade formar intelectuais, pensadores, seres humanos. (COÊLHO, 2016, p. 100).

Considerar as universidades como instituições, e não organizações, significa valorizar uma gestão democrática, "[...] formar intelectuais, pensadores, seres humanos" (COÊLHO, 2016). A própria legislação atual e as metas propostas pelo Plano Nacional de Educação (PNE 2014-2024) indicam a importância da implementação da gestão democrática nas instituições públicas de ensino. Para que esta ocorra em todas as instituições de ensino, seja pública ou privada, de maneira efetiva e com qualidade e relevância social, é indispensável que as universidades propiciem as condições para este fim.

Diante da problemática levantada, surgiu o interesse em realizar uma investigação sobre as características das Instituições de Ensino Superior (IES) do estado do Paraná, a fim de buscar compreender a formação dos(as) coordenadores(as), bem como sua atuação e como ocorre o provimento dos cargos para gestão.

\section{PERCURSO METODOLÓGICO DA PESQUISA}

Muito mais que do mundo que o cerca, a pesquisa exala o interior do pesquisador. Conscientes ou não, a cada linha escrita, o pesquisador sublinha, esconde ou revela suas crenças e seus pressupostos filosóficos e, "[...] por vezes, são visões profundamente arraigadas quanto aos tipos de problemas que precisamos estudar, que perguntas de pesquisa fazer ou como iremos fazer a coleta de dados" (CRESWELL, 2014, p. 29).

Essas crenças e visões, como pontuadas por Creswell (2014), são frutos de uma longa construção identitária e formativa do sujeito pesquisador e nem o 
mais exímio cientista está impune a deixar suas marcas em sua escrita. Todavia conhecer os pressupostos filosóficos que norteiam a pesquisa pode ser de grande valia para o bom êxito metodológico da escrita.

Seguindo essa lógica, a forma como o presente trabalho foi construído buscou na primeira parte deixar claro quais "lentes" e pressupostos teórico-filosóficos os autores adotam na concepção e visão de mundo por eles defendidos.

Assim, optou-se por desenvolver uma pesquisa com abordagem qualitativa. Denzin e Lincoln (2011 apud CRESWELL, 2014, p. 49) descrevem a pesquisa qualitativa como sendo uma atividade

[...] situada que localiza o observador no mundo. A pesquisa qualitativa consiste em um conjunto de práticas materiais interpretativas que tornam o mundo visível. Essas práticas transformam o mundo. Elas transformam o mundo em uma série de representações, incluindo notas de campo, entrevistas, conversas, fotografias, registros e lembretes para a pessoa. Nesse nível, a pesquisa qualitativa envolve uma abordagem interpretativa e naturalística do mundo. Isso significa que os pesquisadores qualitativos estudam coisas dentro dos seus contextos naturais, tentando entender, ou interpretar, os fenômenos em termos dos significados que as pessoas Ihes atribuem.

A partir desse pressuposto básico, a pesquisa qualitativa dá voz aos silenciados e empodera-os a compartilhar suas histórias e experiências em um círculo hermenêutico-dialético, que promove um "processo de construção e de interpretação hermenêutica de um determinado grupo [...] através de um vai-e-vem constante entre as interpretações e re-interpretações sucessivas (dialética) dos indivíduos" (ALLARD, 1996, p. 50-1).

No percurso metodológico da pesquisa, foi realizado um levantamento do número de instituições de educação superior existentes no Paraná. Dados como ano de fundação, quantidades de cursos de graduação existentes e número de matrículas na graduação foram priorizados.

No segundo momento da pesquisa, foi elaborado um questionário ${ }^{2} \mathrm{com}$ perguntas que contemplassem os aspectos identitários sobre a formação e a atuação dos(as) coordenadores(as) dos cursos de graduação, bem como o processo de escolha para o exercício do cargo. A aplicação do questionário, com perguntas abertas e fechadas, tinha por objetivo conhecer os aspectos da formação, atuação

$\overline{2}$ O projeto foi submetido ao Comitê de Ética e, após aprovado, foi emitido o parecer n. 536.847. 
e provisão dos cargos de coordenação e, a partir desses dados gerados, analisar "ideias, crenças, maneiras de pensar; [...] condutas; projeções para o futuro; razões conscientes ou inconscientes de determinadas atitudes e comportamentos" (MINAYO, 2013, p. 262).

Pela extensão de cursos e coordenadores(as), optou-se por um recorte que abrangeria apenas as instituições classificadas como Universidades. Após essa delimitação, foi enviado por e-mail um link com o questionário on-line aos(às) coordenadores(as) de cursos de graduação (bacharelado, tecnólogo, licenciatura) das dezesseis universidades presentes no estado do Paraná.

A utilização de questionários com respostas on-line vem crescendo nas pesquisas educacionais no Brasil, todavia, como toda pesquisa, conta com suas vantagens e desvantagens no levantamento de dados. As principais vantagens observadas é a facilidade que o sujeito investigado tem de responder às questões em curto espaço de tempo, com privacidade e permanecendo em seu local de trabalho. Entretanto, o pesquisador que recorre à utilização de pesquisas on-line corre o risco de ter baixos índices de respostas e não ter acesso aos demais tipos de linguagens que o ator social investigado utiliza para responder ao questionário, como expressões, descontentamentos, períodos reflexivos etc.

Os e-mails encaminhados aos(às) coordenadores(as) de universidades continham uma breve explicação do estudo, o termo de consentimento livre e esclarecido (TLC) e o link utilizado para responder ao questionário. Precauções como confiabilidade do software de pesquisa, anonimato dos respondentes e contato com os pesquisadores envolvidos também integraram o e-mail explicativo da pesquisa.

O questionário enviado contou com 30 questões abertas e fechadas. Os dados gerados receberam tratamento matemático-quantitativo, realizados em planilha eletrônica, gráficos e tabelas de valores percentuais dos resultados.

Retornaram 53 questionários totalmente preenchidos, das dezesseis universidades pesquisadas. Por questões éticas, os nomes das instituições universitárias, bem como dos(as) coordenadores(as), foram omitidos, a fim de garantir o anonimato dos respondentes.

$\mathrm{Na}$ análise dos dados, foi utilizada a técnica de "Análise de Conteúdo" (BARDIN, 2009), optou-se por essa estratégia, pois "[...] tudo o que é dito ou escrito é suscetivel de ser submetido a uma análise de conteúdo" (HENRY; MOSCOVICI, 1968 apud BARDIN, 2009, p. 38). 
A análise contou com três fases: "1. A pré-análise; 2. A exploração do material; e, por fim, 3. O tratamento dos resultados: a inferência e a interpretação" (BARDIN, 2009, p. 121).

Após as análises dos dados gerados, a investigação suscitou a elaboração de um referencial teórico acerca do conceito de gestão escolar e uma análise na legislação educacional, no que diz respeito à formação, a sua normatização e ao provimento dos cargos de gestores.

\section{GESTÃO EDUCACIONAL DEMOCRÁTICA}

Empreender uma discussão acerca da gestão educacional implica necessariamente levar em conta a complexidade que essa temática exige e que no campo teórico nem sempre há um efetivo consenso entre os estudiosos. Porém é de extrema importância entender a epistemologia do termo para posteriormente analisar as respostas obtidas pelos gestores das universidades paranaenses.

Autores como Carlos Roberto Jamil Cury (2002), Vitor Paro (1996), José Carlos Libâneo (2004) e Heloisa Lück (2011) são unânimes em definir a gestão como a atividade organizada, planejada e interativa que mobiliza meios e recursos para se atingir determinados objetivos.

Para Lück (2011, p. 21), gestão é

[...] vê-la como um processo de mobilização da competência e da energia de pessoas coletivamente organizadas para que, por sua participação ativa e competente, promovam a realização, o mais plenamente possível, dos objetos de sua unidade de trabalho, no caso, os objetivos educacionais.

Nessa perspectiva apontada por Lück (2011), a gestão assume uma conceitualização intimamente ligada à participação, à realização e ao sucesso dos objetivos propostos pela instituição educacional. Dessa maneira,

O conceito de gestão, portanto, parte do pressuposto de que o êxito de uma organização social depende da mobilização da ação construtiva conjunta de seus componentes, pelo trabalho associado, mediante reciprocidade que cria um "todo" orientado por uma vontade coletiva. Esta, aliás, é condição fundamental para que a educação se processe de forma efetiva no interior da escola, tendo em vista a complexidade e a importância de seus objetivos e processos. (LÜCK, 2011, p. 21-2).

A própria natureza do trabalho educacional exige um esforço coletivo e compartilhado, de tal maneira que, segundo Cury (2002, p. 165), a gestão “[...] é a geração 
de um novo modo de administrar uma realidade e é, em si mesma, democrática já que traduz pela comunicação, pelo desenvolvimento coletivo e pelo diálogo".

Como descrito por Cury (2002), a democracia assume um papel primordial no desempenho e sucesso na qualidade da gestão educacional. Mas, afinal, o que é gestão democrática?

Peroni (2012, p. 26) argumenta que a gestão democrática

[...] é parte do projeto de construção da democratização da sociedade brasileira. Nesse sentido, a construção do projeto político-pedagógico, a participação em conselhos, a eleição para diretores, a autonomia financeira, são processos pedagógicos de aprendizagem da democracia, tanto para a comunidade escolar, quanto para a comunidade em geral, porque a participação, depois de muitos e muitos anos de ditadura, é um longo processo de construção.

A própria legislação educacional indica que o modelo de gestão a ser adotado na educação pública seja a gestão democrática. Pode-se observar isso no Artigo 206 da Constituição da República Federativa do Brasil de 1988 (BRASIL, 1988) e também na Lei de Diretrizes e Bases da Educação Nacional (LDBEN), n. 9.394, de 1996, que estabelece a gestão democrática como um dos princípios da educação básica e da educação superior (BRASIL, 1996). No entanto uma gestão democrática não pode ser exclusividade das instituições públicas, pois é papel das universidades, seja pública, seja privada, quando imbuídas da sua finalidade de formação humana, criar um espaço democrático, no qual toda comunidade universitária possa participar de forma efetiva no cotidiano da instituição.

Libâneo (2004 p. 104) considera que uma gestão democrática-participativa

[...] se baseia na relação orgânica entre a direção e a participação dos membros da equipe. Acentua a importância da busca de objetivos comuns assumidos por todos. Defende uma forma coletiva de tomada de decisões sem, todavia, desobrigar as pessoas da responsabilidade individual. Ou seja, uma vez tomadas as decisões coletivamente, cada membro da equipe deve assumir sua parte no trabalho.

A gestão educacional deve exprimir nas instituições educacionais os princípios democráticos que norteiam a sociedade brasileira, de tal maneira que "a democracia tem de ser a perspectiva principal de uma escola" pois "só é possível considerar o processo educativo em seu conjunto, sob a condição de se distinguir a democracia como possibilidade no ponto de partida e a democracia como realidade, no ponto de chegada" (SAVIANI, 1983, p. 63). 
E, nessa perspectiva, "a gestão democrática só o é mediante uma prática que articule a participação de todos, o desempenho administrativo-pedagógico e o compromisso sociopolítico". Impondo-se "como crítica das versões autoritárias até então vigentes", a instituição educacional, quando pautada em princípios democráticos, "passa a ser um espaço crítico" (CURY, 2007, p. 9), de garantia e respeitos aos princípios democráticos que norteiam a Constituição Federal.

Dessa maneira, ao se entender a prática educativa como uma atividade que de forma alguma pode ser considerada neutra, sem carregar consigo um caráter político-social e que seu objetivo é a formação de sujeitos críticos, autônomos, cultural e intelectualmente emancipados, a democracia torna-se indispensável à promoção de uma gestão relevante e de qualidade social.

A formação de professores(as) e gestores(as), na perspectiva democrática dos espaços escolares, deve se configurar "como um processo de desvelamento ideológico e de exercício de interpretação de mundo, promovendo a autonomia do pensar". E, nesse processo, os(as) profissionais da educação "devem conseguir reunir, ao longo da sua formação, condições de reflexão crítica para perceber a Educação como um campo de conflitos e de regulação social, permeado por questões de poder" (BISSOTO; MIRANDA; HILKER, 2017, p. 23).

A gestão democrática desafia a instituição de um poder soberano na escola e convida toda a comunidade acadêmica para definir estratégias e tomar decisões em prol do coletivo, do êxito de uma educação de qualidade, com relevância social e situada historicamente, que desempenhe um "papel estratégico [...] como mola propulsora para a transformação e não como instrumento de manutenção de status quo das desigualdades sociais e educacionais" (GONZALEZ; BERNARDO, 2013, p. 65).

A partir dessa conceitualização acerca da gestão escolar e da importância que a gestão democrática assume na qualidade e relevância social da educação, o presente estudo tem a preocupação de investigar os processos de eleição e formação dos professores e professoras que assumem a gestão das instituições universitárias do estado do Paraná.

\section{INSTITUIÇÕES UNIVERSITÁRIAS DO PARANÁ}

A educação superior no Paraná, assim como em todo o país, apresentou, nas últimas décadas, significativa expansão, tanto no setor público como no setor privado. No setor público, observou-se, segundo Sguissardi (2008, p. 996), a cria- 
ção de 12 universidades federais, além do Reuni, que teve impacto no aumento de matrículas, no entanto o crescimento do setor privado foi muito maior e ainda contempla a grande parte de matrículas.

Segundo o Censo da Educação Superior, realizado anualmente pelo Instituto Nacional de Estudos e Pesquisas Educacionais Anísio Teixeira (Inep), o Brasil conta com 2.448 instituições de educação superior. Desse total, 12,30\% das IES são públicas e 87,70\% são instituições privadas de educação superior (BRASIL, 2016).

A tipologia e a organização das instituições de Educação Superior foram definidas pelo Decreto n. 9.235, que, em seu artigo 15, classifica as IES como: "IFaculdades, II- Centros Universitários e III- Universidades" (BRASIL, 2017).

Caracteriza-se como universidade:

[...] instituições pluridisciplinares de formação dos quadros profissionais de nível superior, de pesquisa, de extensão e de domínio e cultivo do saber humano, que se caracterizam por:

I- produção intelectual institucionalizada mediante o estudo sistemático dos temas e problemas mais relevantes, tanto do ponto de vista científico e cultural, quanto regional e nacional;

II- um terço do corpo docente, pelo menos, com titulação acadêmica de mestrado ou doutorado;

III- um terço do corpo docente em regime de tempo integral". (BRASIL, 1996).

O número de IES no Brasil, de acordo com o censo de 2016, é de 2.407, entre públicas e privadas, das quais 197, o equivalente a 8,2\% do total, são Universidades. Por outro lado, as Universidades concentram 53,7\% das matrículas em cursos de graduação, um total de 4.322.092 matrículas. Os centros universitários representam 6,9\% das IES, com o total de 166, e juntos detêm o número de 1.415.147 matrículas nos cursos de graduação, representando $17,6 \%$ das matrículas. São 2.004 faculdades existentes no país, as quais atingem $26,7 \%$ do total de matrículas em cursos de graduação no Brasil, com 2.146.870 matrículas nas IES brasileiras. Os Institutos Federais (IFs) e Centros Federais de Educação Tecnológica (Cefets) são contabilizados pelo Censo da Educação Superior de 2016 em 40, representando $1,7 \%$ do total das IES e possuindo 164.592 matrículas em cursos de graduação, o que representa 2,0 \% do total de matrículas (BRASIL, 2016).

As Universidades são caracterizadas como sendo instituições de Educação Superior pluridisciplinares e que devem promover a indissociabilidade entre o ensino, a pesquisa e a extensão. A legislação brasileira também determina que um 
terço do corpo docente deva possuir a titulação de mestrado e doutorado e trabaIhar em regime de dedicação em tempo integral. Neves (2002, p. 48) recorda que

As universidades gozam de autonomia didático-científica, administrativa e de gestão financeira e patrimonial, devendo obedecer ao princípio de indissociabilidade entre ensino, pesquisa e extensão. É conferida às universidades autonomia para criar, organizar e extinguir cursos e programas de educação superior; fixar os currículos de seus cursos e programas; aumentar ou diminuir o número de vagas, de acordo com a capacidade de atendimento e as exigências do seu meio; contratar e dispensar professores; estabelecer planos de carreira docente; elaborar e formar seus estatutos e regimentos, de acordo com as normas gerais em vigor; estabelecer programas de pesquisa científica, produção artística e atividades de extensão; celebrar contratos como entidade jurídica; administrar receita pública e privada; e receber doações e heranças.

O estado do Paraná conta com 16 IES caracterizadas como universidades. Das 16 universidades, sete são estaduais, cinco são universidades privadas e quatro universidades integram o sistema federal de educação superior.

As universidades estaduais, grande maioria no estado do Paraná, são fiscalizadas e geridas pelo próprio Estado. Sampaio (2000, p. 115-6) comenta que

As universidades estaduais, embora estejam submetidas às mesmas normas legais do sistema de ensino superior, não são financiadas pelo governo federal e sim com recursos dos estados onde estão localizadas. A interface dessas instituições com o governo central ocorre de forma esporádica mediante o pleito de recursos financeiros adicionais. Todavia, deve ser lembrado que embora não exista esse financiamento direto para a manutenção das universidades estaduais, boa parte dos recursos para a pesquisa desenvolvida em algumas dessas universidades é oriunda de agências de fomento de âmbito federal, como o Conselho Nacional de Desenvolvimentos Científico e Tecnológico (CNPq) e a Financiadora de Estudos e Projetos (Finep), vinculados ao Ministério de Ciência e Tecnologia e ainda à Coordenação de Aperfeiçoamento do Ensino Superior (Capes), vinculada ao Ministério da Educação e do Desporto.

Já as universidades privadas paranaenses apresentam enorme heterogeneidade. São instituições confessionais, filantrópicas, comunitárias ${ }^{3}$ e aquelas geridas

3 As universidades comunitárias autodenominam-se "públicas não estatais" e caracterizam-se por manter um elevado grau de interação no contexto social. São criadas e mantidas por conselhos integrados, por membros da comunidade municipal e estadual. Voltam-se muito mais às atividades de ensino e de extensão (BRASIL, 1996). 
com fins lucrativos que "[...] são mantidas e administradas por pessoas físicas ou jurídicas de direito privado" (BRASIL, 1996).

As universidades federais de educação superior são subordinadas e mantidas pela União, que deverá "[...] assegurar, anualmente, em seu orçamento geral, recursos suficientes para manutenção e desenvolvimento das instituições de educação superior por ela mantidas" (BRASIL, 1996).

E, como já mencionado, "[...] as instituições públicas de educação superior obedecerão ao princípio da gestão democrática, assegurada a existência de órgãos colegiados deliberativos, de que participarão os segmentos da comunidade institucional, local e regional" (BRASIL, 1996). O corpo docente deverá ocupar "[...] setenta por cento dos assentos em cada órgão colegiado e comissão, inclusive nos que tratarem da elaboração e modificações estatutárias e regimentais, bem como da escolha de dirigentes" (BRASIL, 1996). Observa-se que no estado do Paraná há grande diversidade de instituições de educação superior e mesmo de universidades quando considerado o tipo de instituição, pública ou privada, com ou sem fins lucrativos.

\section{GESTORES DAS UNIVERSIDADES DO ESTADO DO PARANÁ}

O perfil dos(as) coordenadores(as) de curso das universidades paranaenses é bastante heterogêneo. Cerca de $58,49 \%$ são do sexo masculino e $41,51 \%$ do feminino, dados interessantes ao se considerar que o magistério brasileiro é predominantemente exercido pelo sexo feminino, todavia, as posições de poder e de ascensão aos cargos de tomada de decisões ainda são altamente generificadas na sociedade (HENNERICH PACHECO; FILIPAK, 2017).

A idade predominante dos(as) respondentes (Tabela 1) é de 31 a 40 anos, com 53\% dos profissionais, sendo que os(as) demais possuem idade de até 30 anos, com 9\%; 41 a 50 anos, com 25\%; e nenhum(a) acima de 60 anos.

Tabela 1 - Idade dos(as) gestores(as)

\begin{tabular}{|c|c|}
\hline Idade & Porcentagem \\
\hline até 30 anos & $9 \%$ \\
\hline de 31 a 40 anos & $53 \%$ \\
\hline de 41 a 50 anos & $25 \%$ \\
\hline de 51 a 60 anos & $13 \%$ \\
\hline Total & $\mathbf{1 0 0 \%}$ \\
\hline
\end{tabular}

Fonte: os autores, com base nos dados da pesquisa (2018). 
Percebe-se que a predominância da faixa dos 30 anos de idade dos coordenadores revela gestores(as) jovens. A formação inicial deles é de diversas áreas, entre licenciaturas e bacharelados, sendo predominante, entre os respondentes, a formação em engenharia.

Devido às transformações constantes na sociedade e a necessidade de o(a) professor(a) estar continuamente se aprimorando, faz-se necessária a formação continuada, preparando o profissional da educação para os desafios encontrados no dia a dia do exercício de suas funções.

Conforme corrobora Marilena Chauí (2003, p. 11), o processo de formação dos educadores deve ser permanente, pois, segundo a autora,

[...] diante de um mundo globalizado e em transformação constante, a educação permanente ou continuada é uma estratégia pedagógica indispensável, pois somente com ela é possível a adaptação às mudanças incessantes, se quiser manter-se ativo no mercado de trabalho. A educação permanente ou continuada significa que a educação não se confunde com os anos escolares; isto é, a educação deixa de ser preparação para a vida e torna-se educação durante toda a vida.

Desse modo, pode-se verificar que os(as) coordenadores(as) dos cursos de graduação das universidades do Paraná preocupam-se com a formação continuada, pois $64,58 \%$ possuem especialização, $86,54 \%$ mestrado, $58 \%$ doutorado e $2,63 \%$ realizaram estágios pós-doutoral. No entanto cabe ressaltar que, embora de fundamental importância a formação continuada em cursos de lato e stricto sensu, a formação para a atuação como gestor(a) não pode ser ignorada pela instituição.

Esta formação tem sido realizada em cursos de pós-graduação lato e stricto sensu específicos sobre gestão ou em cursos de formação continuada desenvolvidos pelas instituições. Tais formações são essenciais para quem assume um cargo de gestão em razão das inúmeras incumbências que são atribuídas aos gestores, no entanto, quando nos referimos à gestão democrática, nem sempre tal objetivo é atingido.

Locatelli (2017, p. 80-1) faz referência à reestruturação produtiva do capital e sua influência no trabalho docente com repercussão no ambiente de trabalho e em novas formas de gestão. Evidencia as mudanças que ocorreram no ambiente de trabalho, o qual já não se constitui mais em um local previsível e onde o tempo 
de trabalho já não se limita mais a um local fixo, uma vez que é mediado pelas tecnologias de comunicação, e no qual a competição generalizada se constitui em um obstáculo para uma prática coletiva com impacto na gestão.

Conforme Lêda, Mancebo e Silva Júnior (2016, p. 746), "[...] a organização e a gestão universitária, mediante a reforma do aparelho do Estado, alteram-se de forma estrutural, trazendo para o centro da identidade institucional a racionalidade econômica" e explicam que é a partir desta reforma que ocorrem mudanças entre as quais as relacionadas ao financiamento, à organização, gestão, avaliação, importância dos rankings, expansão e internacionalização da educação superior. Tais transformações requerem que os(as) gestores(as) sejam preparados(as) para os novos desafios, isto é, como criar espaços para uma gestão democrática em um contexto marcado pela ênfase no mercantilismo.

Ante as novas exigências educacionais decorrentes das transformações estruturais da educação superior e as demandas de novos paradigmas que priorizem a formação do todo, e não das partes fragmentas, o(a) gestor(a), muito além de normatizar rituais acadêmicos, passa a exercer uma nova função, qual seja, a de "[...] organizar as ações, trabalhar na diversidade, conviver com outras opiniões e estabelecer trocas mútuas" (CARVALHO, 2012, p. 210-1).

Até mesmo as políticas públicas de formação de professores(as) sugerem essa nova prerrogativa confiada aos(às) gestores(as). De acordo com Carvalho (2009), com base nos novos paradigmas,

[...] as políticas públicas atuais conferem ao administrador escolar uma importância estratégica. A descentralização operacional aumentou as responsabilidades da escola, levando seu gestor a se defrontar com novos desafios, assumir o papel de coordenador da ação dos diferentes componentes do sistema educacional na tomada de decisões conjuntas, estimular o trabalho em equipe e as dinâmicas de trabalho identificadas de sua escola e resolver seus problemas de forma autônoma. Ele torna-se o elemento central e fundamental para o encaminhamento do processo participativo no interior de sua escola e para sua integração com a comunidade (CARVALHO, 2009, p. 1155).

As novas atribuições ao cargo de gestor(a) podem ser uma explicação plausível à constante formação continuada dos entrevistados dessa pesquisa. Além da formação continuada, a experiência em sala de aula figura-se como importante aliado na função da gestão educacional. 
Dos(as) coordenadores(as) respondentes, 28\% possuem experiência de 3 a 5 anos na docência, 27\% relatam que possuem experiência de 6 a 10 anos no magistério, 15\% possuem mais de 15 anos de docência, $11 \%$ responderam que exercem a carreira de professor há mais de 20 anos e $2 \%$ dos gestores estão há mais de 30 anos na docência, dados que podem ser observados na Tabela 2.

Tabela 2 - Tempo de experiência na docência

\begin{tabular}{|c|c|}
\hline Tempo de docência & Porcentagem \\
\hline de 3 a 5 anos & $28 \%$ \\
\hline de 6 a 10 anos & $27 \%$ \\
\hline mais de 10 anos & $17 \%$ \\
\hline mais de 15 anos & $15 \%$ \\
\hline mais de 20 anos & $11 \%$ \\
\hline mais de 30 anos & $2 \%$ \\
\hline Total & $\mathbf{1 0 0 \%}$ \\
\hline
\end{tabular}

Fonte: os autores, com base nos dados da pesquisa (2018).

Em relação ao tempo dedicado à coordenação do curso, as respostas foram variadas. Cerca de $2 \%$ dos respondentes dedicam-se até 5 horas semanais, $6 \%$ até 10 horas, $8 \%$ dedicam-se até 15 horas, 23\% até 20 horas semanais, 26\%, a grande maioria, dedicam-se até 25 horas na coordenação, 13\% até 30 horas, 8\% até 35 horas e 15\% dedicam-se até 40 horas semanais em atividades referentes à coordenação de cursos de graduação.

Do contexto investigado, quando questionados acerca de quanto tempo exercem a função de gestores da instituição em que atuam, as respostas podem ser observadas na Tabela 3.

Tabela 3 - Tempo em que exercem a função de gestores na atual instituição

\begin{tabular}{|c|c|}
\hline Tempo de exercício na gestão & Porcentagem \\
\hline Até 2 anos & $47 \%$ \\
\hline de 3 a 5 anos & $34 \%$ \\
\hline de 6 a 10 anos & $15 \%$ \\
\hline de 11 a 15 anos & $2 \%$ \\
\hline de 16 a 20 anos & $2 \%$ \\
\hline Total & $100 \%$ \\
\hline
\end{tabular}

Fonte: os autores, com base nos dados da pesquisa (2018). 
De acordo com as respostas obtidas, há uma predominância no período em que o(a) gestor(a) atua de 3 a 5 anos na coordenação de curso, e 4\% dos gestores(as) estão exercendo essa função no período que compreende 11 anos até 20 anos.

Em relação às atribuições que os(as) gestores(as) vivenciam em sua prática de coordenação, observa-se na Tabela 4 que as atividades são múltiplas e dependem muito do contexto social em que o gestor atua. Quando questionados acerca das atribuições desempenhadas na coordenação do curso, os(as) participantes da pesquisa poderiam indicar mais de uma resposta, sendo elas:

Tabela 4 - Atribuições como coordenador de curso

Funções exercidas na gestão

\begin{tabular}{|l|l|}
\hline Atualização do Projeto Pedagógico do Curso & 51 \\
\hline Participação no Projeto Pedagógico do Curso & 51 \\
\hline Coordenação de Eventos & 36 \\
\hline Participação de Eventos & 39 \\
\hline Participação na Câmara de Graduação & 18 \\
\hline Participação no Conselho Universitário & 14 \\
\hline Participação em Comitês ou Comissões & 40 \\
\hline Participação em processo seletivo na contratação de professores & 44 \\
\hline Acompanhamento dos alunos com necessidades especiais & 31 \\
\hline Atendimento aos alunos do curso & 53 \\
\hline Atendimento aos professores do curso & 50 \\
\hline Acompanhamento do processo de ensino aprendizagem dos alunos & 50 \\
\hline Acompanhamento do desenvolvimento do plano de ensino dos professores & 45 \\
\hline Entrevistas nos meios de comunicação & 34 \\
\hline Mediação de conflitos & 47 \\
\hline Coordenação do colegiado do curso & 53 \\
\hline Coordenação em outras reuniões pedagógicas & 43 \\
\hline Outros & 15 \\
\hline Fonte: os autors, com base nos dados da pesquisa (2018).
\end{tabular}

Fonte: os autores, com base nos dados da pesquisa (2018).

Como observado na Tabela 4, a diferença numérica de resposta é bastante pequena. Para Libâneo (2004, p. 217), muito além de coordenar as atividades acadêmicas dos cursos, os gestores devem responder pelas seguintes atividades: 
1. Supervisionar e responder por todas as atividades administrativas e pedagógicas da escola bem como as atividades com os pais e a comunidade e com outras instâncias da sociedade civil.

2. Assegurar as condições e meios de manutenção de um ambiente de trabalho favorável e de condições materiais necessárias à consecução dos objetivos da escola, incluindo a responsabilidade pelo patrimônio e sua adequada utilização.

3. Promover a integração e a articulação entre a escola e a comunidade próxima, com o apoio e iniciativa do Conselho de Escola, mediante atividades de cunho pedagógico, científico, social, esportivo, cultural.

4. Organizar e coordenar as atividades de planejamento e do projeto pedagógico-curricular, juntamente com a coordenação pedagógica, bem como fazer o acompanhamento, avaliação e controle de sua execução.

5. Conhecer a legislação educacional e do ensino, as normas emitidas pelos órgãos competentes e o Regimento Escolar, assegurando o seu cumprimento. 6. Garantir a aplicação das diretrizes de funcionamento da instituição e das normas disciplinares, apurando ou fazendo apurar irregularidade de qualquer natureza, de forma transparente e explícita, mantendo a comunidade escolar sistematicamente informada das medidas.

7. Conferir e assinar documentos escolares, encaminhar processos ou correspondências e expedientes da escola, de comum acordo com a secretaria escolar.

8. Supervisionar a avaliação da produtividade da escola em seu conjunto, incluindo a avaliação do projeto pedagógico, da organização escolar, do currículo e dos professores.

9. Buscar todos os meios e condições que favoreçam a atividade profissional dos pedagogos especialistas, dos professores, dos funcionários, visando à boa qualidade do ensino.

10. Supervisionar e responsabilizar-se pela organização financeira e controle das despesas da escola, em comum acordo com o Conselho de Escola, pedagogos especialistas e professores. (LIBÂNEO, 2004, p. 217).

Como apontado por Libâneo (2004), é essencial que o(a) gestor(a) tenha conhecimento do conjunto de fatores que movimentam a instituição de ensino da qual ele faz parte. Por isso, faz-se necessária uma formação contínua e permanente de professores, para que, atualizando-se acerca das questões pertinentes da gestão, eles possam melhor exercer essa função e garantir um processo de qualidade nas relações estabelecidas dentro da instituição.

Acerca da formação continuada dos professores(as) para o exercício da gestão, quando questionados se a instituição oferecia cursos de formação continuada 
na área de gestão escolar, 43\% apontaram que sim, que a instituição oferece e incentiva a participação em cursos de aperfeiçoamento e $57 \%$ responderam que as instituições não ofereciam cursos à formação de gestores.

Sobre o financiamento desses cursos, 53\% responderam que a instituição não disponibiliza recursos financeiros à formação para o exercício de gestão e $47 \%$ responderam que a instituição financiava cursos de formação permanente ao exercício da gestão.

O processo de escolha do(a) professor(a) para o cargo de gestor(a) também se mostrou diverso. Para $28 \%$, o processo ocorreu por eleições, $66 \%$ dos respondentes disseram que o provimento do cargo deu-se por indicação - da reitoria, do antigo(a) gestor(a) dos colegas docentes - e para $6 \%$ o processo foi realizado por uma lista tríplice de indicados dentre os docentes de carreira efetiva da instituição ou por escolha direta da reitoria da instituição.

Entre os(as) gestores(as) que foram eleitos, $87 \%$ eram do sexo masculino e apenas $13 \%$ do sexo feminino, número que se inverte no processo de indicação, em que $52 \%$ das gestoras indicadas eram do sexo feminino e $48 \%$, do sexo masculino. Novamente, esses dados revelam a forte desigualdade de gênero presente nas relações de poder da sociedade.

Ao se comparar esses dados do Censo da Educação Superior em 2017, percebe-se que, mesmo tendo crescido a inclusão das mulheres nos cursos superiores e sendo uma maioria na atualidade (BRASIL, 2016), sua presença ainda é inferior entre os cargos de tomada de decisões e entre áreas acadêmicas consideradas de maior prestígio social. Para mudar este fato, é necessário: "transformar as culturas acadêmicas de diferentes departamentos, cursos, disciplinas e áreas do conhecimento, para erradicar obstáculos e formas de discriminação, desvalorização e exclusão sutis baseados em sinas de gênero" (CARVALHO; MONTANÉ, 2012, p. 9).

\section{CONSIDERAÇÕES FINAIS}

A gestão está presente em todos os processos educativos, administrativos, sociais, culturais, enfim, em todos os processos que as instituições universitárias assumem no seu cotidiano, daí a importância do seu estudo. Preservar as instituições, cuja existência é fundamental para a democracia no país, é fundamental, em especial, nestes tempos em que se vive uma crise nas democracias. Como descreve Santos (2016, p. 125), com a emergência do neoliberalismo, foi se consti- 
tuindo uma democracia representativa de baixa intensidade, que requer vigilância constante para que se fortaleça o caminho no sentido de uma democracia social. Como muito bem argumenta Snyder (2017, p. 22), "[...] são as instituições que nos ajudam a preservar a democracia. Elas também precisam da nossa ajuda".

As universidades carregam um potencial para contribuir com o fortalecimento da democracia ao instituírem no seu interior uma gestão democrática. Neste estudo, evidenciou-se que na gestão de cursos de graduação a atuação do(a) gestor(a) vai além de meras tarefas burocráticas; desde o contato direto com os estudantes até as demandas apresentadas pelo corpo docente, o(a) gestor(a) precisa estar atento às diversas situações cotidianas que movimentam as instituições de educação superior, daí sua importância de estar em constante diálogo com a comunidade acadêmica.

No entanto constata-se pelas respostas obtidas que há uma predominância de escolha de gestores(as) por indicação e mais de 50\% dos(as) coordenadores(as) sinalizam que não existe um processo de formação continuada que forneça subsídios para o desenvolvimento de habilidades essenciais que contribuem para a qualidade do planejamento e da gestão das atividades acadêmicas; embora o número de gestores indicados seja elevado, observa-se nas atividades indicadas por eles a predominância de atividades pedagógicas e aquelas voltadas a uma gestão colegiada.

\section{REFERÊNCIAS}

ALLARD, Denis. De l'évaluation de programme au diagnostic socio-systémique: trajet épistémologique. 1996. Thèse (Doctoraat em Sociologie) - Université du Quèbec á Montréal, Montréal, 1996.

BALL, Stephen John. Educação global S.A. Novas redes políticas e o imaginário neoliberal. Ponta Grossa, PR: UEPG, 2014.

BARDIN, Laurence. Análise de conteúdo. Lisboa, Portugal: Edições 70/LDA, 2009.

BISSOTO, Maria Luisa; MIRANDA, Antonio Carlos; HILKNER, Regiane Rossi. A articulação entre a formação de professores e o ensino-pesquisa socialmente comprometidos. Série-Estudos - Periódico do Programa de Pós-Graduação em Educação da UCDB, Campo Grande, MS, v. 22, n. 46, p. 17-36, set./dez. 2017. Disponível em: http://www.serieestudos.ucdb.br/index.php/serie-estudos/article/view/1051. Acesso em: 16 maio 2019. 
BRASIL. Ministério da Educação. Decreto n. 9.235. Dispõe sobre o exercício das funções de regulação, supervisão e avaliação das instituições de educação superior e dos cursos superiores de graduação e de pós-graduação no sistema federal de ensino. Diário Oficial da União, Brasília, DF, 2017. Disponível em: http://www.planalto.gov.br/ccivil_03/_Ato20152018/2017/Decreto/D9235.htm. Acesso em: 10 ago. 2018.

BRASIL. Ministério da Educação. Instituto Nacional de Estudos e Pesquisas Educacionais Anísio Teixeira. Censo Escolar da Educação Superior 2016. Brasília, DF, 2016. Disponível em: http://download.inep.gov.br/educacao_superior/censo_superior/documentos/2016/ notas_sobre_o_censo_da_educacao_superior_2016.pdf >. Acesso em: 3 out. 2018.

BRASIL. Ministério da Educação. Lei de Diretrizes e Bases da Educação Nacional, n. 9.394. Estabelece as diretrizes e bases da Educação Nacional. Diário Oficial da União, Brasília, 1996. Disponível em: http://www.planalto.gov.br/ccivil_03/leis/l9394.htm. Acesso em: 15 ago. 2017.

BRASIL. Presidência da República. Constituição da República Federativa do Brasil. Brasília, 1988. Disponível em: http://www.planalto.gov.br/ccivil_03/constituicao/constituicao. htm. Acesso em: 10 ago. 2018.

CARVALHO, Elma Júlia Gonçalves de. Políticas públicas e gestão da educação no Brasil. Maringá: Eduem, 2012.

CARVALHO, Elma Júlia Gonçalves de. Reestruturação produtiva, reforma administrativa do Estado e gestão da educação. Educação \& Sociedade, Campinas, SP, v. 30, n. 109, p. 1139-66, set./dez. 2009.

CARVAlHo, Maria Eulina Pessoa de; MONTANÉ, Alejandra. Políticas de equidade de gênero na educação superior na Espanha e no Brasil: avanços e limites. Labrys, Estudos Feministas, jul./dez. 2012. Disponível em: https://www.labrys.net.br/labrys22/education/ maria\%20eulina.htm. Acesso em: 27 nov. 2019.

CHAUÍ, Marilena. A universidade pública sob nova perspectiva. Revista Brasileira de Educação, Rio de Janeiro, n. 24, p. 5-15, set./dez. 2003. Disponível em: http://www. scielo.br/scielo.php?pid=S1413-24782003000300002\&script=sci_abstract\&tlng=pt $>$. Acesso em: 15 ago. 2018.

COÊLHO, Ilda Moreira. Universidade e ensino: treino ou formação? In: COÊLHO, I. M.; FURTADO, R. M. M. (Org.). Universidade, cultura, saber e formação. Campinas, SP: Mercado das Letras, 2016. p. 87-107. 
CRESWELL, John W. Investigação qualitativa e projeto de pesquisa escolhendo entre cinco abordagens. 3. Porto Alegre: Penso, 2014.

CURY, Carlos Roberto Jamil. Gestão democrática da educação em tempos de contradição. In: Simpósio Brasileiro de Política e Administração da Educação, 23. Cadernos Anpae, n. 4, 2007.

CURY, Carlos Roberto Jamil. Gestão democrática da educação: exigências e desafios. Revista brasileira de Política e Administração da Educação, São Bernardo do Campo, SP, v. 18, n. 2, p. 163-74, jul./dez. 2002.

GONZALEZ, Wânia; BERNARDO, Elisangela. A gestão democrática em espaços não formais de ensino. Série-Estudos - Periódico do Programa de Pós-Graduação em Educação da UCDB, Campo Grande, MS, n. 36, p. 63-76, jul./dez. 2013. ISSN 2318-1982. Disponível em: http://www.serie-estudos.ucdb.br/index.php/serie-estudos/article/view/697. Acesso em: 16 maio 2019.

HENNERICH PACHECO, Eduardo Felipe; FILIPAK, Sirley Terezinha. Relações de gênero e diversidade sexual na educação. Psicologia Argumento, Curitiba, v. 35, n. 88, p. 63-81, jan./ abr. 2017. Disponível em: https://periodicos.pucpr.br/index.php/psicologiaargumento/ article/view/23364. Acesso em: 4 out. 2018.

LÊDA, Denise Bessa; MANCEBO, Deise; SILVA JÚNIOR, João dos Reis. O trabalho nas instituições de educação superior. Revista Brasileira de Política e Administração da Educação, [S.I.], v. 32, n. 3, p. 739-57, set./dez. 2016.

LIBÂNEO, José Carlos. Organização e gestão da escola: teoria e prática. Goiânia: Alternativa, 2004.

LOCATELLI, Cleomar. Os professores no ensino superior brasileiro: transformações do trabalho docente na última década. Revista Brasileira de Estudos Pedagógicos, Brasília, v. 98, n. 248, p. 77-93, jan./abr. 2017.

LÜCK, Heloisa. A gestão participativa na escola. Petrópolis, RJ: Vozes, 2011.

MINAYO, Maria Cecília de Souza. O desafio do conhecimento. Pesquisa qualitativa em saúde. 4. ed. São Paulo: Hucitec-Abrasco, 2013.

OLIVEIRA, João Ferreira. Os papéis sociais e a gestão das universidades federais no Brasil. In: SIMPÓSIO BRASILEIRO DE POLÍTICA E ADMINISTRAÇÃO DA EDUCAÇÃO, 26., 2013, Recife. Anais [...]. Recife, 2013. Disponível em: http://www.anpae.org.br/ 
Instituições de educação superior do Paraná: atuação e formação de coordenadores de curso para uma gestão democrática

simposio26/1comunicacoes/joaoFerreira-ComunicacaoOral-int.pdf. Acesso em: 9 abr. 2018.

PARO, Vitor Henrique. Eleições de diretores: a escola pública experimenta a democracia. Campinas, SP: Papirus, 1990.

PERONI, Vera Maria Vidal. A gestão democrática da educação em tempos de parceria entre público e privado. Pro-Posições [on-line], Campinas, SP, v. 23, n. 2, p. 19-31, maio/ ago. 2012. Disponível em: http://www.scielo.br/scielo.php?script=sci_arttext\&pid=S0103$73072012000200003 \&$ Ing=en\&nrm=iso. Acesso em: 16 maio 2019.

SAMPAIO, Helena. O ensino superior no Brasil: o setor privado. São Paulo: Hucitec, 2000.

SANTOS, Boaventura de Souza. A difícil democracia: reinventar as esquerdas. São Paulo: Boitempo, 2016.

SAVIANI, Dermeval. Para além da curvatura da vara. Revista da ANDE, São Paulo, n. 3, 1983.

SEVERINO, Antônio Joaquim. Prefácio. In: COÊLHO, I. M.; FURTADO, R. M. M. (Org.). Universidade, cultura, saber e formação. Campinas, SP: Mercado das Letras, 2016. p. 7-12.

SGUISSARDI, Valdemar. Modelo de expansão da educação superior no Brasil: predomínio privado/mercantil e desafios para a regulação e a formação universitária. Educação \& Sociedade, Campinas, SP, v. 29, n. 105, p. 991-1022, set./dez. 2008. Disponível em: http:// www.scielo.br/scielo.php?script=sci_arttext\&pid=S0101-73302008000400004\&lng=en\& nrm=iso. Acesso em: 29 nov. 2019.

SNYDER, Timothy. Sobre a tirania: vinte lições do século XX para o presente. São Paulo: Companhia das Letras, 2017.

\section{Sobre os autores:}

Eduardo Felipe Hennerich Pacheco: Doutorando em Educação pela Pontifícia Universidade Católica do Paraná (PUCPR). Bolsista da Coordenação de Aperfeiçoamento de Pessoal de Nível Superior (CAPES). E-mail: eduardo.pva@hotmail.com, Orcid: http://orcid.org/0000-0003-1498-2351

Sirley Terezinha Filipak: Doutora em Educação (PUCPR). Professora do Programa de Pós-Graduação em Educação da Pontifícia Universidade Católica do Paraná (PUCPR). E-mail: sirley.filipak@pucpr.br, Orcid: https://orcid.org/0000-0003-4264-1626 
Maria Lourdes Gisi: Doutora em Educação pela Universidade Estadual Paulista (UNESP). Professora do Programa de Pós-Graduação em Educação da Pontifícia Universidade Católica do Paraná (PUCPR). E-mail: gisi.marialourdes@gmail.com, Orcid: http://orcid.org/0000-0002-0474-474X

Antonio de Souza Júnior: Mestre em Educação pela Pontifícia Universidade Católica do Paraná (PUCPR). Diretor de ensino da Prefeitura Municipal de Jaraguá do Sul e coordenador adjunto do Curso de Medicina na Estácio, unidade Jaraguá do Sul, SC. E-mail: id9850@jaraguadosul.sc.gov.br, Orcid: http://orcid.org/0000-0002-1316-8422

Recebido em 4 de outubro de 2018 Aprovado em 31 de outubro de 2019 